\title{
Synthesis of Biodiesel from Transesterification of Jatropha Oil with Methanol Using Double Metal Cyanide as Catalyst
}

\author{
Praveen Kumar, Vimal Chandra Srivastava, and Mithilesh K. Jha
}

\begin{abstract}
Fe-Zn double-metal cyanide catalysts were synthesized by co-reaction of zinc chloride with potassium ferrocyanide in presence co-complexing agent and complexing agent. Acidity, basicity, morphology and textural characteristics of catalysts were studied using $\mathrm{CO}_{2^{-}}$and $\mathrm{NH}_{3^{-}}$ temperature-programmed desorption (TPD), X-ray diffraction (XRD), scanning electron microscopy (SEM) and liquid $\mathrm{N}_{2}$-sorption data. $\mathrm{Fe}-\mathrm{Zn}-1$ catalyst with highest basicity was found to be more effective for transesterification of Jatropha oil with methanol to form biodiesel in a batch reactor. It was further used for optimizing the reaction condition such as effect of methanol/PC molar ratio and reaction time; and studying its reusability.
\end{abstract}

Index Terms-Transesterification of Jatropha oil, Fe-Zn double metal cyanide, Biodiesel.

\section{INTRODUCTION}

Biodiesel is green alternative fuels resource. It is a non-toxic, biodegradable, renewable alternative of the conventional diesel fuel. Biodiesel has lower emission, no sulfur content, high flash point and high centane number [1]-[3]. High production cost and insufficient feedstock are the major hurdles in the very large scale production of biodiesel. In this context, low cost non-edible oil such as karanja oil, Jatropha oil, waste cooking oil, etc. can improve the economical feasibility of the production of biodiesel [1]-[3].

Various types of homogeneous catalysis (acid and base) are used for the synthesis of biodiesel due to faster conversion and high yield. However, homogeneous catalyst has many drawbacks such as equipment corrosion, tedious separation process due to formation of emulsion, removal of catalyst and its disposal. To overcomes these problem, heterogeneous catalysts such as $\mathrm{CaO}, \mathrm{ZnO}, \mathrm{SrO}, \mathrm{Al}_{2} \mathrm{O}_{3} \mathrm{ZrO}_{2}$ and $\mathrm{MgO}$ are used for biodiesel production. However, low yield, reuseability and leaching are some of the drawbacks of these atalysts [4], [5]. In the present study, Fe-Zn based double metal cyanide catalyst was synthesized and used for biodiesel production. A series of double metal cyanide (DMC) particularly $\mathrm{Fe}-\mathrm{Zn}$ catalyst were synthesized and used for

Manuscript received July 9, 2015; revised December 25, 2015

Praveen Kumar and Vimal Chandra Srivastava are with the Department of Chemical Engineering, Indian Institute of Technology Roorkee, Roorkee 247667, Uttarakhand, India (e-mail: praveen.zon@gmail.com, vimalcsr@yahoo.co.in, vimalfch@iitr.ac.in).

Mithilesh K. Jha is with the Department of Chemical Engineering, National Institute of Technology, Jalandhar 144001, Punjab, India (e-mail: jhamkin@yahoo.co.in). transesterification of Jatropha oil to produce biodiesel. The synthesized catalysts were characterized for $\mathrm{N}_{2}$-sorption, X-ray diffraction (XRD), $\mathrm{NH}_{3}$ - and $\mathrm{CO}_{2}$-TPD for studying acidity, basicity and morphology of the catalysts using scanning electron microscopy (SEM). The synthesized catalysts were then tested for biodiesel production from transesterification of Jatropha oil with methanol.

\section{EXPERIMENTAL}

\section{A. Materials}

Zinc chloride hydrous $\left(\mathrm{ZnCl}_{2}\right)$ and Potassium ferrocyanide $\left(\mathrm{K}_{4}\left[\mathrm{Fe}(\mathrm{CN})_{6}\right]\right)$ and were purchased from Himedia Chemical, India. Methanol and tert-butanol were purchased from Loba chemical, India. Poly (ethylene glycol)-block-poly (propylene glycol)-block-poly (ethylene glycol) (PEG-5800) was purchased from Aldrich chemical, India. All chemicals were used of analytical grade (AR). Deionized water was obtained from Milli- $Q$ water filtration station (Millipore).

\section{B. Catalyst Preparation}

For synthesis of Fe-Zn catalyst, potassium ferrocyanide $(0.01 \mathrm{~mol})$ was dissolved in deionized water $(40 \mathrm{~mL})$ used for prepration of solution 1 . In the another beaker, $\mathrm{ZnCl}_{2}(0.1 \mathrm{~mol})$ dissolved in deionized water $(100 \mathrm{~mL})$ and tert-butanol $(20$ $\mathrm{mL})$ to prepare solution 2 and in another beaker $15-\mathrm{g}$ of tri-block copolymer(PEG-5800), $40 \mathrm{~mL}$ of tert-butanol and 2 $\mathrm{mL}$ deionized water were added in a third beaker to prepare solution 3. After that, the solution 2 was added drop-wise to the solution 1 at $50^{\circ} \mathrm{C}$ for $1 \mathrm{~h}$ under vigorous stirring till white color precipitate was formed. After that, solution 3 was added under vigorous stirring condition at $50^{\circ} \mathrm{C}$ for 5-10 min to the product formed from solution 1 and 2 . The solution was further stirred for $2 \mathrm{~h}$ at room temperature. The white colour precipitate was washed with deionized water to remove all of the uncomplexed ions and dried at room temperature for $24 \mathrm{~h}$ and then activated at $180^{\circ} \mathrm{C}$ for $6 \mathrm{~h}(\mathrm{Fe}-\mathrm{Zn}-1)$. PEG-5800 works as a co-complexing agent and tert-butanol acts as a complexing agent. Fe-Zn-2 catalyst was prepared in absence of co-complexing agent (PEG-5800) and Fe-Zn-3 in absence of both complexing agent (tert-butanol) and co-complexing agent (PEG-5800) agents for synthesis [6], [7].

\section{Catalyst Characterization}

The Fe-Zn catalysts were characterized by various characterization techniques such as $\mathrm{N}_{2}$-sorption, XRD, $\mathrm{NH}_{3}$-TPD, $\mathrm{CO}_{2}$-TPD, SEM-EDX and ICP-OES. Textural properties of the synthesized catalysts were investigated with 
micromeritics ASAP 2020 at $-195^{\circ} \mathrm{C}$ using $\mathrm{N}_{2}$ sorption. Specific surface areas and pecific pore volumes of the catalysts were estimated with Brunauer-Emmett-Teller (BET) and Barrett-Joyner-Halenda (BJH) method, respectively. XRD pattern of catalysts were estimated with Brueker AXS, Germany with D8 diffractometer $(40 \mathrm{kV} / 30 \mathrm{~mA})$ with $(\lambda=$ $1.5406 \AA)$ at $\mathrm{Cu} \mathrm{K} \alpha$ radiation with step size 0.02 over a $2 \theta$ range of $5^{\circ}-60^{\circ}$. Crystalline size was investigated with ICDD-JCPDS. Crystal sizes $(L)$ and lattice strain were calculated from the Scherrer's equation:

$$
L=\frac{K \lambda}{\beta \cos \theta}
$$

where, $K$ is the Scherrer's constant $(K=0.94), \beta$ is the full width of the reflection at half maximum (FWHM), $\lambda$ is the wavelength of X-ray radiation is equal to $1.54051 \AA$, and $\theta$ is the Bragg angle. Acidic and basic properties of the synthesized catalysts were determined by TPD of $\mathrm{NH}_{3}$ and $\mathrm{CO}_{2}$ with micromeritics Chemisorb (model- 2720) with (TCD) thermal conductivity detector. The sample $(50 \mathrm{mg})$ was placed in a quartz U-tube for $6 \mathrm{~h}$ at $200^{\circ} \mathrm{C}$ under helium flow. Adsorption/saturation of $\mathrm{NH}_{3}$ was performed with 20 $\mathrm{cm}^{3} \mathrm{~min}^{-1}$ flow rate for $30 \mathrm{~min}$ after that dispersed with helium for $1 \mathrm{~h}$ at room temperature. The desorption of $\mathrm{NH}_{3}$ was investigated from $30-900^{\circ} \mathrm{C}$ at $10^{\circ} \mathrm{C} \mathrm{min}^{-1}$ under helium flow $\left(20 \mathrm{~cm}^{3} \mathrm{~min}^{-1}\right)$ and evolved $\mathrm{NH}_{3}$ was estimated with TCD detected. Similarly, same process was used for $\mathrm{CO}_{2}$-TPD to estimate the acidic properties of the catalysts. Elemental compositions and morphology were determined by SEM-EDX from Model 200-FEG, QUANTA, Netherlands at $15 \mathrm{kV}$. Actual metal composition estimated with the EDXRF spectrometer (MiniPal-2) from PANayltical, Netherlands.

\section{Catalytic Activity}

Catalytic activity of the synthesized catalysts was tested for transesterification of Jatropha oil with methanol for biodiesel synthesis in a stainless-steel autoclave $(500 \mathrm{~mL})$ reactor attached with mechanical stirrer. Initially, the reaction was filled with required amounts of Jatropha oil, catalysts and methanol and the reactor was flushed with nitrogen. The reactor was heated with desired temperature with heating rate of $10{ }^{\circ} \mathrm{C} \cdot \mathrm{min}^{-1}$ and with constant stirring $450 \mathrm{~min}^{-1}$. The progress of reaction was studies by Thin Layer Chromatography (TLC), solution was prepared with the composition of glacial acetic acid $(1.5 \mathrm{ml})$ : diethyl ether $(13.5$ $\mathrm{ml})$ : petroleum ether $(85 \mathrm{ml})$ mixture as the mobile phase. After completion of the reaction, the product mixture was transferred to separate from glycerin with catalyst in lower phase and biodiesel in upper phase. The product was estimated in terms of conversion (\%) by using Gel Permeation Chromatography (GPC) technique, which consist PL gel column $(5 \mathrm{~nm} \times 7.5 \mathrm{~mm})$ with refractive index detector $\mathrm{THF}$ as carrier solvent with flow rate $1 \mathrm{~cm}^{3} \cdot \mathrm{min}^{-1}$.

\section{RESULTS AND DISCUSSION}

\section{A. Catalyst Characterization}

$\mathrm{N}_{2}$ sorption. Specific surface area $\left(\mathrm{S}_{\mathrm{BET}}\right)$ of $\mathrm{Fe}-\mathrm{Zn}-1$,
$\mathrm{Fe}-\mathrm{Zn}-2$ and $\mathrm{Fe}-\mathrm{Zn}-3$ were found to be $125 \mathrm{~m}^{2} \cdot \mathrm{g}^{-1}, 85 \mathrm{~m}^{2} \cdot \mathrm{g}^{-1}$ and $75 \mathrm{~m}^{2} \cdot \mathrm{g}^{-1}$, respectively. Pore volume of $\mathrm{Fe}-\mathrm{Zn}-1$, $\mathrm{Fe}-\mathrm{Zn}-2$ and $\mathrm{Fe}-\mathrm{Zn}-3$ were found to be $0.1395 \mathrm{~cm}^{3} \cdot \mathrm{g}^{-1}$, $0.0308 \mathrm{~cm}^{3} \cdot \mathrm{g}^{-1}$ and $0.0355 \mathrm{~cm}^{3} \cdot \mathrm{g}^{-1}$, respectively (see Table I). All the catalysts exhibit type IV isotherm with $\mathrm{H} 3$ hysteresis (see Fig. 1(a)), which corresponds to porous substances with wide range of pore sizes. Such porous substances show adsorption behavior extending from monolayer to multilayer and ultimately to capillary condensation.

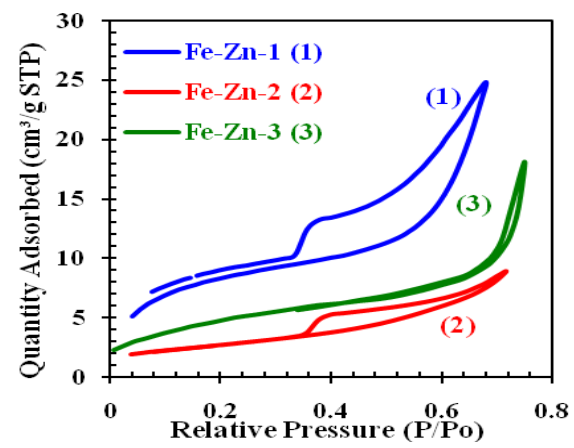

(a)

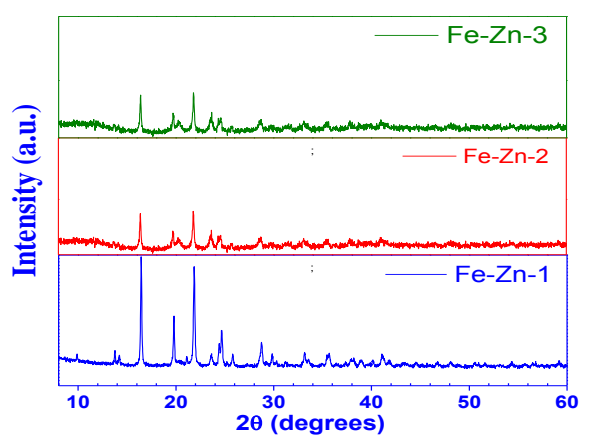

(b)

Fig. 1. $\mathrm{N}_{2}$ adsorption-desorption isotherm \& XRD of the synthesized catalysts.

TABLE I: $\mathrm{N}_{2}$ SORPTION AND METAL COMPOSITION OF THE SYNTHESIZED CATALYSTS

\begin{tabular}{ccccccccc}
\hline Catalyst & $\begin{array}{c}\text { BET } \\
\text { Surface } \\
\text { Area } \\
\left(\mathrm{m}^{2} \cdot \mathrm{g}^{-1}\right)\end{array}$ & $\begin{array}{c}\text { Pore } \\
\text { Volume } \\
\left(\mathrm{cm}^{3} \cdot \mathrm{g}^{-1}\right)\end{array}$ & $\begin{array}{c}\text { Actual } \\
\text { values }\end{array}$ & \multicolumn{2}{c}{$\begin{array}{c}\text { Actual values } \\
\text { from ED-XRF } \\
\text { analysis }\end{array}$} & \multicolumn{2}{c}{$\begin{array}{c}\text { Actual } \\
\text { values from } \\
\text { EDX }\end{array}$} \\
analysis \\
$\mathrm{Fe}-\mathrm{Zn}-1$ & 126 & 0.139 & 0.4 & 0.6 & 0.39 & 0.61 & 0.38 & 0.62 \\
\hline $\mathrm{Fe}-\mathrm{Zn}-2$ & 85 & 0.030 & 0.4 & 0.6 & 0.38 & 0.62 & 0.39 & 0.61 \\
\hline $\mathrm{Fe}-\mathrm{Zn}-3$ & 71 & 0.035 & 0.4 & 0.6 & 0.38 & 0.62 & 0.38 & 0.62 \\
\hline
\end{tabular}

XRD. X-ray diffraction patterns of synthesized $\mathrm{Fe}-\mathrm{Zn}$ catalysts are shown in the Fig. 1(b). The synthesized catalysts are highly crystalline. XRD patterns of Fe-Zn-1 catalyst showed peaks at 16.45 (111), 19.84 (200), 21.91 (210), 24.64 (211), and 28.84 (221) corresponding to a cubic structure with space group of Fm-3m. Fe-Zn-1, Fe-Zn-2 and Fe-Zn-3 catalyst formed hydrated $\mathrm{K}_{2} \mathrm{Zn}_{3}\left[\mathrm{Fe}(\mathrm{CN})_{6}\right]_{2} \cdot x \mathrm{H}_{2} \mathrm{O}$, hydrated $\mathrm{K}_{2} \mathrm{Zn}_{3}\left[\mathrm{Fe}(\mathrm{CN})_{6}\right]_{2}$ and hydrated $\mathrm{K}_{2} \mathrm{Zn}_{3}\left[\mathrm{Fe}(\mathrm{CN})_{6}\right]_{2}$, respectively. Fe-Zn-1 catalyst was found to possess $19.6 \mathrm{~nm}$ crystalline size and 0.0125 lattice strain. Fe-Zn-2 and Fe-Zn-3 were prepared in absence of complexing and co-complexing agents but with difference reagents and could be indexed to a mixture of cubic [6], [7].

$\mathbf{N H}_{3}$-TPD. Acidity of the synthesized catalysts was performed by $\mathrm{NH}_{3}-\mathrm{TPD}$ and the results are shown in Fig. 2(a) and Table II. The $\mathrm{CO}_{2} / \mathrm{NH}_{3}$-TPD profiles are classified such 
as: weak, moderate, and strong with the temperature range corresponding $\left(<200^{\circ} \mathrm{C}\right),\left(200-450^{\circ} \mathrm{C}\right)$ and $\left(>450^{\circ} \mathrm{C}\right)$, respectively. The basic site density depends upon the temperature at which peaks exist. Low temperatures desorption of the $\mathrm{NH}_{3}$ as weak basic sites in the catalysts and higher temperature desorption of $\mathrm{NH}_{3}$ shows strong basic sites. The total amount of $\mathrm{NH}_{3}$ desorbed from the $\mathrm{Fe}-\mathrm{Zn}-3$, $\mathrm{Fe}-\mathrm{Zn}-2$, and Fe-Zn-1 catalysts was: $16.83,11.16$ and 18.54 mmol.g ${ }^{-1}$, respectively. Total desorbed amount of $\mathrm{NH}_{3}$ was found to be in the following order: $\mathrm{Fe}-\mathrm{Zn}-2<\mathrm{Fe}-\mathrm{Zn}-3<$ $\mathrm{Fe}-\mathrm{Zn}-1$. Fe-Zn-1 catalyst is found to posses highest acidic sites in all regions. Overall the co-complexing agent and complexing agent affect the acidic properties of the catalysts.

TABLE II: TPD ANALYSIS USING ABSORBED $\mathrm{NH}_{3}$ AND $\mathrm{CO}_{2}$ OF SYNTHESIZED CATALYSTS

\begin{tabular}{|c|c|c|c|c|}
\hline \multirow[b]{2}{*}{ Catalyst } & \multicolumn{3}{|c|}{ TPD analysis of absorbed $\mathrm{NH}_{3}(\mathrm{mmol} / \mathrm{g})$} & \multirow{2}{*}{$\begin{array}{c}\begin{array}{c}\text { Total } \\
\text { evolved } \mathrm{NH}_{3} \\
(\mathrm{mmol} / \mathrm{g})\end{array} \\
\end{array}$} \\
\hline & $\begin{array}{l}\text { Weak }(< \\
\left.200^{\circ} \mathrm{C}\right)\end{array}$ & $\begin{array}{l}\text { Moderate } \\
\left(200-450^{\circ} \mathrm{C}\right)\end{array}$ & $\operatorname{Strong}\left(>450^{\circ} \mathrm{C}\right)$ & \\
\hline Fe-Zn-1 & - & - & $\begin{array}{l}13.66 \quad(548), \quad 1.31 \\
(612) \& 3.57(785)\end{array}$ & 18.54 \\
\hline Fe-Zn-2 & - & - & $\begin{array}{l}7.19 \quad(515), \quad 3.95 \\
(764) \& 0.65(847)\end{array}$ & 11.16 \\
\hline \multirow[t]{2}{*}{ Fe-Zn-3 } & $6.55(89)$ & $0.15(334)$ & $\begin{array}{l}1.93(539) 2.01(760) \\
\& 6.19(848)\end{array}$ & 16.83 \\
\hline & \multicolumn{3}{|c|}{ TPD analysis of absorbed $\mathrm{CO}_{2}(\mathrm{mmol} / \mathrm{g})$} & Tot \\
\hline Catalyst & $\begin{array}{l}\text { Weak } \\
\left(<200^{\circ} \mathrm{C}\right)\end{array}$ & $\begin{array}{l}\text { Moderate } \\
\left(200-450^{\circ} \mathrm{C}\right)\end{array}$ & Strong $\left(>450^{\circ} \mathrm{C}\right)$ & $\begin{array}{l}\text { evolved } \mathrm{CO}_{2} \\
(\mathrm{mmol} / \mathrm{g})\end{array}$ \\
\hline Fe-Zn-1 & $0.61(106)$ & $\begin{array}{l}0.29(229) \\
0.63(430)\end{array}$ & $\begin{array}{c}\& 4.51(558), \quad 0.71 \\
\quad(694) \& 4.69(843)\end{array}$ & 11.44 \\
\hline Fe-Zn-2 & - & - & $\begin{array}{l}3.57(524), 1.94 \\
(689) \& 3.01(788)\end{array}$ & 8.52 \\
\hline Fe-Zn-3 & $0.74(110)$ & $\begin{array}{l}0.67 \quad(239) \\
0.85(416)\end{array}$ & $\begin{array}{ccc}\& 2.39 & (600), & 1.45 \\
& (737) \& 1.99(835)\end{array}$ & 8.09 \\
\hline
\end{tabular}

Temperature $\left({ }^{\circ} \mathrm{C}\right)$ at maxima is given in brackets.

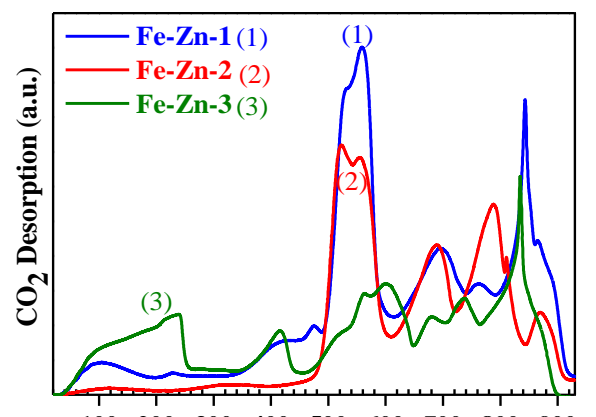

$\begin{array}{lllllllll}100 & 200 & 300 & 400 & 500 & 600 & 700 & 800 & 900\end{array}$ Temperature $\left({ }^{\circ} \mathrm{C}\right)$

(a)

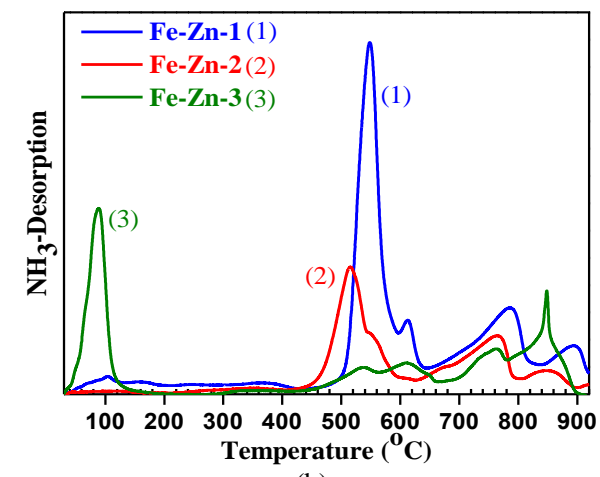

(b)

Fig. 2. $\mathrm{NH}_{3}$ and $\mathrm{CO}_{2}$ TPD of the synthesized catalysts.

CO2-TPD. The basic properties of the synthesized catalysts were investigated by $\mathrm{CO}_{2}$-TPD and results are shown in Fig. 2(b) and $\mathrm{CO}_{2}$ desorption values are shown in Table II. Strong basic sites of medium strength are due to the presence of low-coordinated $\mathrm{O}^{2}$ and presence of $\mathrm{M}^{\mathrm{n}+}-\mathrm{O}^{2-}$ on the surface and weak basic sites are due to surface $\mathrm{O}-\mathrm{H}$ groups. The total amount of $\mathrm{CO}_{2}$ desorbed from the $\mathrm{Fe}-\mathrm{Zn}-1$, $\mathrm{Fe}-\mathrm{Zn}-2$, and Fe-Zn-3 catalysts shows 18.54, 11.16 and $16.83 \mathrm{mmol} . \mathrm{g}^{-1}$, respectively. Total desorbed amount of $\mathrm{CO}_{2}$ was found to be in the following order: Fe-Zn-3 < Fe-Zn- $<$ $\mathrm{Fe}-\mathrm{Zn}-1$. Thus, Fe-Zn-1 catalyst most basic and that the $\mathrm{Fe}-\mathrm{Zn}-3$ is least basic. It may be noted that amount of acidic and basic sites are more in Fe-Zn-1 and this catalysts have been found higher specific surface area as compared toFe-Zn-2 and Fe-Zn-3.

Surface morphology and elemental analysis. SEM image images of the synthesized Fe-Zn-1, Fe-Zn-2 and Fe-Zn-3 catalysts are shown in the Fig. 3. All the catalysts, shows the squire and rectangular morphology, heterogeneous and crystalline structure. Fe-Zn-1 catalysts show sharp cube shaped structure, however, Fe-Zn-2 and Fe-Zn-3 show undeveloped or broken cubes.

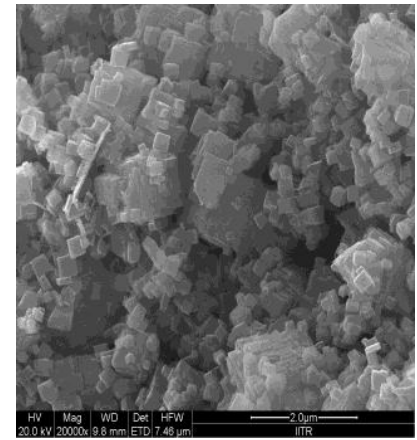

Fe-Zn-1

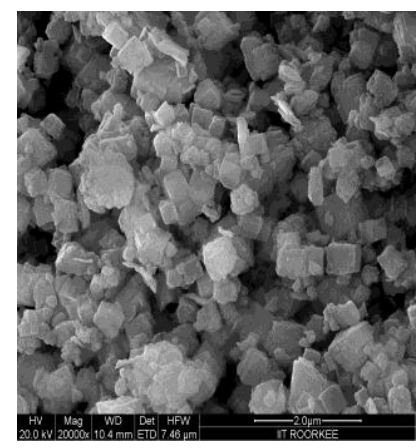

Fe-Zn-2

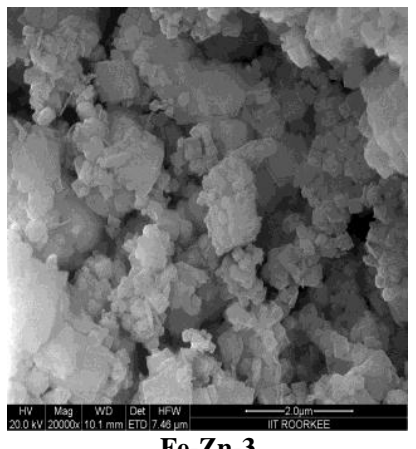

Fe-Zn-3

Fig. 3. SEM image of the synthesized catalysts.

The activity of the Fe-Zn-1, Fe-Zn-2 and Fe-Zn-3 synthesized catalyst were evaluated in terms of ester conversion. Activity of the synthesized catalysts was checked at the initial pressure of 2-5 bar and the final pressure of 20-25 bar; catalyst mass $=3 \mathrm{wt} \%$ of Jatropha oil and reaction temperature $=160{ }^{\circ} \mathrm{C}$.

The effect of reaction time on ester conversion at different reaction time is shown in Fig. 4(a). It can be seen in the Fig. 4(a) that the ester conversion increases with the increases with time up to $180 \mathrm{~min}$ and after that only marginal changes occur in the ester conversion. Fig. 4(b) shows the methanol/Jatropha oil molar ratio on ester conversion. It may be seen that the conversion increased with increase in the methanol/Jatropha oil molar up to a ratio of 12 after that marginal changes in the ester conversion are observed. 


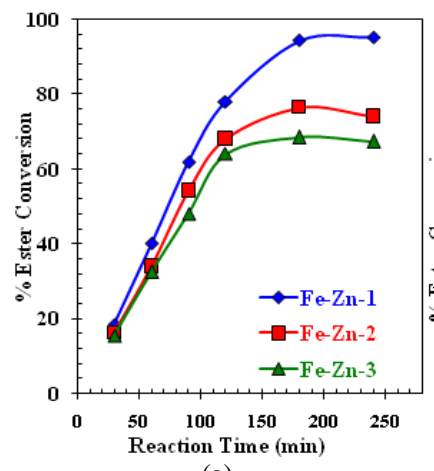

(a)

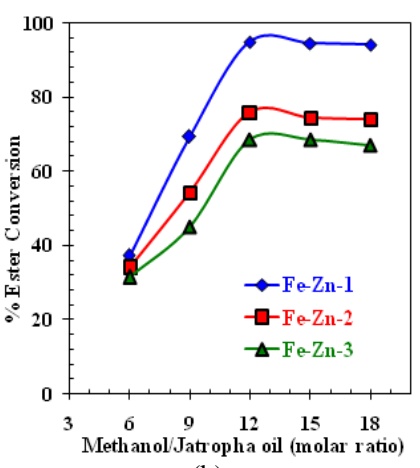

(b)
Fig. 4. (a) Effect of reaction time and, (b) Effect of methanol/ Jatropha oil molar ratio on transesterification reaction.

Fe-Zn-1 catalyst was found to give maximum $94.5 \%$ ester conversion at $3 \mathrm{wt} . \%$ catalyst dose for reaction time of 180 min. Fe-Zn-2 and Fe-Zn-3 catalyst gave only $76.5 \%$ and $68.6 \%$ ester conversion, respectively at these conditions. It can be seen in the catalysts characterization and the activity of the catalysts has reasonable correlation with the basicity and surface area of the catalysts. The recovered (Fe-Zn-1) catalyst was further for tested for reusability of catalyst without any intermediate regeneration process. No significant loss of activity was observed for transesterification of Jatropha oil for 5 runs. Average $93 \%$ conversion was observed in these runs [8], [9].

\section{CONCLUSION}

Fe-Zn double metal cyanide was found to be highly active catalysts for production of biodiesel from transesterification of Jatropha oil with methanol. In the synthesis of catalysts, both cocomplexing agent (PEG-5800) and complexing agent (tert-butabol) were found to significantly affect physical (crystallinity and surface area) and catalytic properties. Fe-Zn-1 catalyst gave maximum $94.5 \%$ ester conversion in $180 \mathrm{~min}$ at $3 \mathrm{wt} . \%$ catalyst dosage with methanol/Jatropha oil molar ratio of 12 and temperature $160^{\circ} \mathrm{C}$. Fe-Zn-2 and Fe-Zn-3 catalyst gave $76.5 \%$ and $68.6 \%$ ester conversion, respectively at these conditions. Basicity and surface area of the catalysts were found to significantly affect the activity of the catalysts.

\section{REFERENCES}

[1] F. Ma and M. A. Hanna, "Biodiesel production: A review," Bioresource Technology, vol. 70, pp. 1-15, Oct. 1999.

[2] H. Fukuda, A. Kondo, and H. Noda, "Biodiesel fuel production by transesterification of oils," Journal of Bioscience and Bioengineering, vol. 92, no. 5, pp. 405-416, 2001.

[3] N. N. A. N. Yusuf, S. K. Kamarudin, and Z. Yaakob, "Overview on the production of biodiesel from Jatropha curcas L. by using heterogenous catalysts," Biofuels, Bioproducts and Biorefining, vol. 6, no. 3, pp. 319-334, 2012

[4] H. V. Lee, J. C. Juan, N. F. B. Abdullah et al., "Heterogeneous base catalysts for edible palm and non-edible Jatropha-based biodiesel production," Chemisrty Central Journal, vol. 8, no. 30, 2014.

[5] S. H. Teo, U. Rashid, and Y. H. Taufiq-Yap, "Biodiesel production from crude Jatropha Curcas oil using calcium based mixed oxide catalysts," Fuel, vol. 136, pp. 244-252, Nov. 2014.

[6] R. Srivastava, D. Srinivas, and P. Ratnasamy, "Fe-Zn double-metal cyanide complexes as novel, solid transesterification catalysts," Journal of Catalysis, vol. 241, no. 1, pp. 34-44, Jul. 2006.

[7] F. Yan, Z.-H. Yuan, P.-M. Lu, W. Luo, L.-M. Yang, and L. Deng, "Fe- $\mathrm{Zn}$ double-metal cyanide complexes catalyzed biodiesel production from high-acid-value oil," Renewable Energy, vol. 36, no. 7, pp. 2026-2031, 2011.

[8] M. Sharma, A. A. Khan, S. K. Puri, and D. K. Tuli, "Wood ash as a potential heterogeneous catalyst for biodiesel synthesis," Biomass and Bioenergy, vol. 41, pp. 94-106, Jun. 2012.

[9] S. Chen, P. Zhang, and L. Chen, "Fe/Zn double metal cyanide (DMC) catalyzed ring-opening polymerization of propylene oxide: Part 3. Synthesis of DMC catalysts," Progress in Organic Coatings, vol. 50 , no. 4, pp. 269-272, 2004.

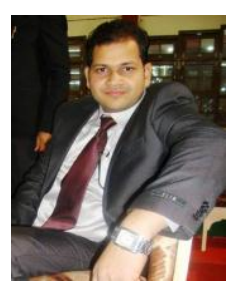

Praveen Kumar was born in Muzaffarnagar, India, in 1984. He received the Ph.D. degree in chemical engineering in Indian Institute of Technology Roorkee in 2015 with specialization in catalysis and reaction engineering. He received M.Tech degree in chemical engineering from National Institute of Technology, Jalandhar in 2009 and B.Tech degree in U.P. Tech Lucknow. He was previously associated with Indian Oil R\&D as a research trainee, and was a lecturer in SLIET, Sangrur; an assistant professor in National Institute of Technology, Jalandhar; and a researcher in Institute of Technology in Leipzig Universität, Germany. He is a DAAD fellow of the Deutscher Akademischer Austauschdienst, Germany. He is currently working as a senior research fellow in the Department of Chemical Engineering in Indian Institute of Technology Roorkee. His research interest is in catalysis, green chemistry and reaction engineering.

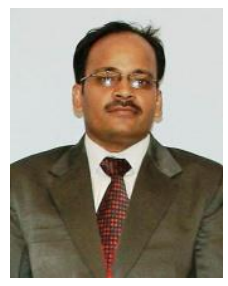

Vimal Chandra Srivastava was born in Raebareli, India, in 1978. Dr. Srivastava is currently serving as an associate professor in the Department of Chemical Engineering, Indian Institute of Technology (IIT), Roorkee, India. He obtained his doctoral degree in chemical engineering from IIT Roorkee in 2006. Prior to his appointment at Roorkee, Dr. Srivastava served as an assistant professor at the Department of Chemical Engineering and Technology, Indian Institute of Technology, Banaras Hindu University, Varanasi, India. His major research interests are in industrial pollution abatement, physico-chemical treatment of industrial wastes, multi-component adsorption, electro-chemical treatment, desulphurization and disposal of spent-adsorbents/catalysts/residues. He has published more than 100 papers in peer-reviewed journals and more than 80 papers in conferences/seminars. He has more than 3800 citations of research papers with h-index of $29 . \mathrm{He}$ has guided $8 \mathrm{PhD}$ thesis, and 6 more are in progress. In addition, he has guided $35 \mathrm{M}$.Tech. dissertations. He was awarded prestigious international award "Prosper.Net-SCOPUS Young Researcher Award 2010 - First Runner-up Prize" for his research work on 'Treatment of Industrial Wastes' at Award symposium held at Tongji University, Shanghai, China, on 5 July 2010. Dr. V.C. Srivastava has been awarded with numerous Top Indian National Awards like "INAE Young Engineers Award 2012" by Indian National Academy of Engineering (INAE); "INSA Young Scientist Medal 2012" by Indian National Science Academy (INSA) in the "Engineering Science Category"; "IE Young Engineer Award 2013" by Institution of Engineers, India in the "Environmental Engineering" division; "Amar Dye-Chem Award 2013" by Indian Institute of Chemical Engineers (IIChE). Dr. Srivastava is a young associate of INAE; member of NASI; fellow of the International Congress of Chemistry and Environment; life member of IIChE, Indian Science Congress Association (ISCA) and Indian Society for Electro-Analytical Chemistry (ISEAC) and associate member of Institution of Engineers, India. He is a reviewer of all the leading journals of chemical and environmental engineering.

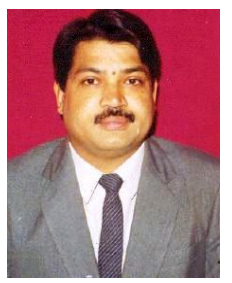

M. K. Jha is presently serving as a professor in the Department of Chemical Engineering, National Institute of Technology (NIT), Jalandhar, Punjab, India. He has guided several $\mathrm{PhD}$. and post-graduate students. He has been previously the dean of academic, dean of students \& alumni, at NIT Jalandhar and the head of the Dept. of Chemical Engineering, Leather Technology, Centre of Training \& Placement at NIT Jalandhar. He was also formerly a visiting professor at Asian Institute of Technology, Bangkok. 